\title{
Construcción de fronteras simbólicas y prácticas religiosas
}

Daniel Solís Domínguez, ${ }^{*}$ Consuelo Patricia Martínez Lozano**

\section{Resumen}

Las creencias y prácticas religiosas constituyen una dimensión relevante y significativa en la sociedad mexicana, hecho que se manifiesta en la constitución de colectividades religiosas heterogéneas. Las formas en que intervienen en la vida pública y la manera en que se relacionan entre ellas son complejas y la mayoría de las veces desconocidas. Este texto presenta un análisis de las interacciones entre diferentes prácticas religiosas. Para ello, se integra la descripción y análisis de una procesión y un desfile. En ambos eventos, las creencias y las prácticas religiosas construyen fronteras simbólicas que operan en una lógica vinculante de límites más que de separación de lo religiosamente diferente, es decir, se entienden como un espacio en donde converge y se cruza lo religiosamente diferente. Se concluye que la construcción de fronteras simbólicas religiosas describe y explica la actual dinámica de relaciones entre las diferentes prácticas religiosas.

Palabras clave: frontera simbólica, práctica religiosa, iglesias, desfile, procesión.

\section{Abstract}

Beliefs and religious practices constitute a relevant and significant dimension in Mexican society, as it is reflected in the constitution of heterogeneous religious communities. The forms in which they take part in public life and the way they relate among them are complex and mostly unknown. This text presents an analysis of the interactions between different religious practices. To this end, integrates the description and analysis of a procession and a parade. In both events, beliefs and religious practices build symbolic borders, which are understood as a space where religious diversity converge and cross. We conclude that the construction of religious symbolic borders describes and explains the current dynamics of relations between the different religious practices.

Keywords: Symbolic borders, religious practices, churches, parades, processions.

* Coordinación de Ciencias Sociales y Humanidades, Universidad Autónoma de San Luis Potosí. Correo electrónico: daniel.solis@uaslp.mx.

** Escuela de Ciencias de la Comunicación, Universidad Autónoma de San Luis Potosí. Correo electrónico: patricia.martinez@uaslp.mx 


\section{Introducción}

Toda práctica o experiencia de los sujetos necesariamente se realiza en un espacio y tiempo, tanto objetivo como subjetivo. Es decir, la experiencia se lleva a cabo en un contexto específico y concreto, localizado en el espacio social y por lo tanto histórico y cultural. De tal manera, las prácticas de los sujetos delimitan y construyen el contexto y, a su vez, el contexto condiciona y moldea las prácticas. Es decir, entre contexto y práctica ocurre una codependencia, una relación dialéctica. Tal codependencia y dialéctica genera un entramado significativo singular distinguible de otras prácticas correspondientes a otros contextos. Esta distinción implica la construcción de límites.

De la misma manera, las prácticas religiosas se realizan en tiempos y espacios objetivos y subjetivos, en contextos con los que mantienen relaciones de codependencia y, debido a esto, configuran entramados de significaciones localizados dentro del campo religioso; es decir, las prácticas religiosas construyen límites, fronteras.

Siguiendo estas ideas, nos proponemos analizar los procesos de construcción de "fronteras simbólicas". La argumentación se centra en plantear que las prácticas religiosas son heterogéneas y en consecuencia construyen múltiples fronteras. Esta multiplicidad se relaciona en la medida en que las fronteras entran en contacto y se compenetran formando una zona de cruces, hecho que genera "zonas fronterizas" (Rosaldo, 1999), "zonas de contacto” (Pratt, 1996), "espacios intersticiales” (Bhabha, 2003) o procesos de "interfaz" (Long, 2007).

La frontera se entiende como un hecho aislante, como la división de una dinámica o complejo interno que distingue un centro alrededor del cual gravitan sus elementos, pero también como un proceso vinculante que permite cruces y contactos, tránsitos de diversos elementos, si bien estas interacciones no se vinculan con el centro para formar parte del complejo interno, sino que se mantienen en los límites.

La frontera implica tanto a un centro como a una periferia que es su límite, que, al cruzarse, figura una topológica social intersticial en la que es posible localizar elementos heterogéneos y descentrados en estado de desplazamiento o en movimiento. En las zonas fronterizas se genera la comunicación y a la vez la tensión entre procesos multirreligiosos y seculares, por lo cual las zonas fronterizas son también arenas de confrontación. 
En la medida que la frontera es comunicante, convoca a sujetos interactuando; sin embargo, no es una interacción predeterminada ni previamente estructurada y euclidiana. Todo lo contrario, es una interacción entre actores o grupos recreada y generada cada vez que se actualiza y se realiza la relación interactiva. En esta orientación, las interacciones son contingentes y emergentes, obedecen más a operaciones estratégicas que a programas estructurantes; en consecuencia, las fronteras también operan así.

Pensamos que las zonas fronterizas religiosas explican parte de la dinámica de transformación que está experimentando el campo religioso en México; no obstante, también queremos intentar, brevemente, dar una respuesta exploratoria a la siguiente pregunta: ¿qué papel tienen estas zonas fronterizas en nuestra sociedad? Es decir, en una sociedad en donde, pese a la diversidad de sociedades religiosas que en los últimos años se han configurado, continúa existiendo un núcleo eclesial católico fuertemente influyente en la vida social, ¿las zonas fronterizas dan cuenta de posicionamientos emergentes de los sujetos religiosos con la fuerza suficiente para minar, contrarrestar y transformar a tal núcleo de poder simbólico?

Esta perspectiva de frontera (y un breve ensayo de respuesta a las preguntas formuladas) se ejemplifica y se explora a través de dos casos empíricos: una procesión católica (la Marcha del Silencio) y un desfile escolar (del 20 de noviembre, en conmemoración de la Revolución mexicana), ambos efectuados en un área popular de la ciudad de Guadalajara, México. Aludir al problema de construcción de frontera simbólica requiere involucrar tres términos cuya diferenciación es preciso captar en el análisis, ya que en la interpretación están compenetrados: cultura, frontera y religión. Enseguida se expone brevemente la relación entre dichos términos.

\section{Frontera, cultura y religión}

El término cultura está implícito en la discusión sobre el concepto de frontera. Así lo señala Grimson (2003) cuando anota:

La propia noción de "cultura" de la antropología fue creadora de fronteras. De hecho una teoría de la frontera es una teoría de la cultura. Concebir la cultura como un todo integrado de costumbres, creencias y prácticas o como significados compartidos por una comunidad implica necesariamente delimitar con precisión conjuntos humanos (Grimson, 2003:14). 
La cultura como un "todo integrado" (Tylor, 1992), como un "conjunto de símbolos articulados" que constituyen un sistema (Geertz, 1990), supone posicionados y relacionados a sus elementos (individuos, procesos, objetos, creencias, etc.); posiciones que, si bien se emplazan en una estructura (abstracta, pensada por los analistas), inevitablemente, aunque la mayor de las veces quede implícito, son referidas a un espacio, a un territorio discreto. Dicho territorio (nacional, regional, local, comunal, pero ahora también global o planetario) es compartido por sus habitantes en virtud de que comparten un conjunto de significados: lengua, valores, una tradición; es decir, la cultura.

Así, el territorio adquiere una lógica funcional, esto es, un elemento del conjunto de significados es comprendido (y se explica) si -y sólo si- está en relación con los demás elementos del sistema. La cultura así entendida tiende hacia el centro y remarca su periferia, cristaliza un núcleo de significados y refuerza sus límites. Prácticas y procesos adquieren una centralidad en la medida en que definen la cultura y la diferencian de otra. Desde esta perspectiva, la frontera hace patente una diferenciación y delimitación inequívoca entre culturas.

Pensar la cultura como "un todo" de elementos articulados trajo como consecuencia la idea de comunidad. Asimismo, esta perspectiva cultural y comunitaria ha hecho posible que el sistema de símbolos no sólo se identifique con un territorio geográfico, sino también con la construcción de fronteras simbólicas (Barth, 1979; Cohen, 1995). En el asunto que nos ocupa, entonces, la cultura evoca una "comunidad con territorio, o sea, fronteras físicas", y también una "comunidad con cultura, es decir con fronteras simbólicas" (Grimson, 2003:14).

En este texto recuperamos el planteamiento de frontera referida a una comunidad emplazada físicamente y a una comunidad simbólica. Lo primero es relevante porque nos ubica dentro de procesos objetivos, por ejemplo, la simbolización del espacio, y esto mismo pone de relieve lo segundo: la creación de fronteras simbólicas. Pero también recuperamos y enfatizamos que, como decíamos, las fronteras son contingentes, se recrean a partir de las prácticas dadas en situaciones singulares en un tiempo y un espacio específicos, es decir, en un contexto social. De este modo se advierte que lo geográfico y lo simbólico no necesariamente se corresponden, es decir, lo segundo no se reduce a lo primero. Lo simbólico es el espacio subjetivo, incalculable y no lineal. 
Ahora bien, siguiendo una definición clásica, religión es:

Un sistema de símbolos que obra para establecer vigorosos, penetrantes y duraderos estados anímicos y motivaciones en los hombres formulando concepciones de un orden general de existencia y revistiendo esas concepciones con una aureola de efectividad tal que los estados anímicos y motivaciones parezcan de un realismo único (Geertz, 1990:89).

Este orden general de existencia formula y figura una cosmovisión (construida por los propios sujetos) que es entendida y practicada a través de un ethos, cristalizado y consagrado en valores enlazados a una acción. Así, la religión opera como "modelo de la realidad" y "modelo para la realidad" (Geertz, 1990). Explica y hace entendible la vida cotidiana (esas "concepciones de un orden general de existencia”) en la que está inmerso el sujeto, al mismo tiempo que proporciona una guía para orientarse en los quehaceres diarios, en la práctica cotidiana. Como cosmovisión, la religión se compenetra con la cultura (pero no es la cultura, lo religioso forma parte constituyente de lo cultural). Religión y cultura conforman un orden social y, en esta orientación, es posible identificar la construcción de una comunidad con fronteras simbólicas. En sociedades como la mexicana, en la que ha ido emergiendo una diversidad religiosa, las comunidades religiosas entran en contacto de múltiples formas constituyendo zonas fronterizas de las cuales hablaremos más adelante.

Aquí nos abocamos a un análisis de estas relaciones entre diferentes comunidades religiosas y entre comunidades religiosas y seculares, así como a estudiar las interacciones entre los sujetos integrantes de tales comunidades, identificándolas -siguiendo a Rosaldo (1999)- como interacciones de "zonas fronterizas".

En este sentido, es necesario poner la atención en las prácticas en la medida en que enriquecen el análisis de construcción de fronteras simbólicas, pues dirigen el análisis no a presupuestos esencialistas, apriorísticos y homogeneizadores, sino a la manera en que los sujetos sociales, las personas, efectivamente construyen las zonas fronterizas y entran en interacción concreta en ellas.

Resumiendo, en sociedades en las cuales se compenetra lo religiosamente diverso con la cultura y en donde las condiciones particulares históricas 
permiten que comunidades religiosas interactúen, se construyen límites. Enfatizamos las prácticas de los sujetos en tales límites porque mediante ellas se construyen tanto las fronteras como las zonas fronterizas, pues sólo mediante las prácticas sustentadas por los individuos concretos son posibles los cruces de límites, es decir, la construcción simbólica de fronteras.

\section{Breve nota metodológica}

Los datos que se presentan a continuación fueron recopilados a partir de estrategias metodológicas cualitativas, fundamentalmente observación directa. Resultado de esto fue un acercamiento etnográfico no sólo a la procesión y al desfile, sino también al contexto en donde ocurrieron, es decir, a las colonias populares.

Cabe decir que el levantamiento de información se dio en un marco más amplio de investigación cuyo objetivo fue interpretar y explicar las relaciones entre prácticas religiosas y seculares (estas últimas, específicamente correspondientes a prácticas escolares de centros educativos públicos de nivel básico; es decir, prácticas orientadas por una perspectiva laica). El periodo en que se realizó la observación en y de las colonias se extiende a lo largo de 12 meses en intervalos diferentes durante tres años. Esto permitió contextualizar tanto la procesión como el desfile, entendiéndolos como situaciones o procesos en los que se expresa una dinámica social específica y particular que comunica procesos de mayor envergadura para la sociedad en su conjunto.

Recurrimos a un análisis situacional pero con miras a la construcción de fronteras simbólicas. Es decir, observamos prácticas de encrucijadas, descentradas, intersticiales y en desplazamiento. Creemos que los procesos rituales en contextos urbanos permiten no sólo circunscribir y describir, sino también ubicar y analizar zonas fronterizas dentro de la vasta extensión social donde transcurre la vida cotidiana de los sujetos. La información sobre la Marcha del Silencio se registró durante abril de 2005, y la respectiva al desfile conmemorativo de la Revolución mexicana, el 20 de noviembre del mismo año. 


\section{Procesión y desfile en colonias populares de la ciudad de Guadalajara}

El área a la que nos referimos se ubica en el oriente de la Zona Metropolitana de la ciudad de Guadalajara. En general, en esta zona se asientan colonias populares y algunas de ellas apenas sobrepasan tres décadas de antigüedad, como Villas de Guadalupe y El Bethel. Ambas colonias son vecinas y comparten elementos comunes: vías de comunicación, servicios urbanos deficientes, habitantes que pertenecen a los estratos económicos de menor ingreso, etcétera. Pareciera, pues, que si uno caminara en las inmediaciones de las colonias, de una hacia otra, no habría ninguna disrupción inmediata respecto al paisaje urbano. Sin embargo, son diferentes, y esta diferencia no sólo es implícita, sino que los mismos habitantes la hacen manifiesta.

La toponimia de cada colonia expresa una voluntad de diferenciación: los nombres de El Bethel y Villas de Guadalupe, por ejemplo, aluden a dos formas de religiosidad opuestas y en ocasiones en conflicto. Además, cabe destacar que no sólo es el nombre de las colonias un reflejo de sus diferencias, sino también el nombre de las calles, de los pequeños comercios e incluso de las instituciones gubernamentales. Esto es evidente en El Bethel, en donde todas las calles y la mayoría de los pequeños comercios llevan nombres de lugares bíblicos (Betania, Eglón, Egipto, etc.), incluyendo a instituciones gubernamentales como el Centro de Salud que lleva el nombre de la colonia. Asimismo, las edificaciones dedicadas a los servicios religiosos son parte de la diferenciación. Mientras que en la colonia El Bethel se ha construido uno de los templos de La Iglesia La Luz del Mundo de mayor tamaño en la ciudad de Guadalajara (y quizá en el país), en Villas de Guadalupe se edificaba, en el momento de la investigación, una parroquia (Nuestra Señora de la Reconciliación) que pretendía ser de grandes proporciones. En otras palabras, los habitantes de ambas colonias han configurado una geografía religiosa diferenciada.

El Bethel es una colonia cuyos habitantes en su mayoría son adherentes a la Iglesia La Luz del Mundo, ${ }^{1}$ mientras que los residentes de Villas de Gua-

1 Esta Iglesia puede caracterizarse grosso modo de acuerdo con los siguientes atributos: disciplina, obediencia, respeto a los valores patrios, sistema de vida comunitario, ética del trabajo y puritana, así como por la apropiación de los valores nacionales y de la historia 
dalupe son, también en su mayoría, católicos. En cada colonia, esta adhesión diferenciada y mayoritaria ha conformado un predominio y hegemonía religiosa. En El Bethel, los católicos integran un grupo disperso que sólo adquiere integración cuando acuden a misas o eventos religiosos relevantes (bautizos, fiestas de santos o santas, casamientos, etcétera), mientras que en Villas de Guadalupe ocurre lo mismo pero con los miembros de La Luz del Mundo (y de otras sociedades religiosas no católicas).

En El Bethel y en Villas de Guadalupe los límites (es decir, las fronteras) obedecen a criterios de administración municipales. De acuerdo con tal criterio, están bien establecidos y mediante ellos no se incurre en errores para aclarar los límites, los cuales corresponden con delimitaciones físicas de la traza urbana. No obstante, en lo que toca a los límites simbólicos, en cada colonia hay una identificación con un núcleo hegemónico religioso, lo cual permite la configuración de comunidades que expresan procesos de dominación anclados al territorio. La hegemonía religiosa hace posible identificar la construcción de territorios identitarios religiosos (Giménez, 1999; Solís, 2009). Sin embargo, predominio o hegemonía no descartan automáticamente la presencia de otros grupos al interior del territorio, por lo cual el proceso de construcción de frontera no sólo se realiza en los límites de la comunidad sino en el interior de la misma. Es decir, se realiza en intersticios, en una "zona fronteriza" en la que se remarca la subordinación y el poder, al mismo tiempo que la oposición y la resistencia. En estas colonias hay procesos que se dirigen, de manera explícita, a construir la diferencia, la frontera, ya sea para ejercer hegemonía o para contrarrestarla. De aquí que en la "zona fronteriza" no sólo estén convocados los procesos de dominación y subordinación, sino también los de resistencia y contrahegemonía. Para analizar tales procesos fronterizos insertaremos breves descripciones de la Marcha del Silencio, procesión organizada por la parroquia de la colonia Villas de Guadalupe, y de un desfile (aparentemente secular) realizado en la colonia El Bethel y organizado por las escuelas públicas situadas en dicha colonia.

oficial del Estado mexicano liberal (por ejemplo, el anticatolicismo y la exaltación de Benito Juárez) (De la Torre, 1995). La Luz del Mundo ha sido eficiente en crear una matriz de identidad consolidada por la integración de valores nacionales y cívicos con los específicamente religiosos. 


\section{La Marcha del Silencio}

La Marcha del Silencio es una procesión correspondiente a las celebraciones de Semana Santa que forma parte de las actividades organizadas por la parroquia de Nuestra Señora de la Reconciliación, ubicada en la colonia Villas de Guadalupe. En las actividades y en la organización participan habitantes de la colonia integrados por grupos -generalmente de jóvenesvinculados a la parroquia. Ese día (9 de abril de 2005), por la mañana se efectuó el "Vía Crucis viviente", y por la tarde, la Marcha del Silencio.

Minutos antes de las siete de la tarde, jóvenes y adolescentes conformaron un grupo que esperaba en la calle frente a la entrada de la parroquia. Hablaban entre ellos, parecía que unos y otros se daban órdenes y tomaban decisiones. Así transcurrieron entre 10 y 15 minutos de preparativos. Este grupo, de alrededor de 40 jóvenes de ambos sexos que en su mayoría vestía de negro, empezó a formar dos filas paralelas.

Antes de iniciar la marcha, uno de los jóvenes -el que daba las instrucciones- dijo: "Hay que tratar de hacerlo con respeto. Recordemos que lo hacemos para acompañar a la Virgen en su dolor, a la madre de Jesucristo por haber perdido a su hijo". Este joven dio instrucciones a otros sobre las "paradas" que iban a hacer a lo largo de la procesión. Cinco o seis jóvenes, mujeres y hombres, portaban cartelones escritos por ambos lados con las palabras "Silencio" y "Alto". Así, cuando se debía hacer alto para cruzar la calle o detenerse en un sitio donde estuviera un altar (previamente instalados para la marcha), los jóvenes debían alzar el cartel de un lado o del otro para que el contingente siguiera o se detuviera. Los jóvenes estaban formados entre la fila, colocados de manera que todos, en el momento indicado, pudiera ver y leer los carteles.

$\mathrm{Al}$ frente de la procesión se colocó un joven con un tambor y tras de él se formaron los encargados de portar diversos objetos: una joven llevaba una Biblia cuyo tamaño la obligaba a usar las dos manos para sostenerla; enseguida, también usando ambas manos, otra joven sostenía un cojín color rojo carmesí sobre el cual había una corona de espinas; tras estas jóvenes, uno más cargaba una cruz de madera casi de su tamaño; por último, entre seis jóvenes llevaban en andas un altar de la Virgen de los Dolores, mismo que había sido sacado del interior del templo. Seguían la procesión los jóvenes restantes y el largo de la fila la constituían los feligreses, habitantes de la 
colonia (mujeres, hombres y niños), que ya para entonces se habían congregado y formado en una de las dos filas paralelas.

A las 19:05 horas se dio la orden de iniciar la marcha. Quien portaba el tambor empezó a golpearlo emitiendo un sonido que marcaba los pasos de los "marchistas". El sonido era lento pero rítmico, grave y monótono; sólo se detenían cuando la procesión "debía” detenerse. Hombres, mujeres y niños caminaban en silencio, reverentes, al ritmo del tambor.

$\mathrm{Al}$ empezar la marcha había alrededor de 100 personas. Durante el recorrido, la procesión fue alargándose, así que al final se congregaron en fila cerca de 250 personas. Sin embargo, así como se integraron, también algunos se desprendieron durante el recorrido. Desde el inicio, la marcha tuvo espectadores: los vecinos salieron de sus hogares para contemplar el paso de la procesión. En muestra de respeto (y de adhesión) guardaban silencio reverencial. La marcha había creado un efecto de solemnidad en quienes caminaban y en quienes observaban; unos y otros constituían un todo integrado, una comunidad.

La marcha se desplazó sobre calles empedradas, con pendientes hacia abajo y hacia arriba. Las casas, en su mayoría, exhibían en sus ventanas pequeños carteles en los cuales, junto a una imagen de Cristo crucificado, se leía: "Este hogar es católico". También en algunas de las casas había imágenes de Cristo o de la Virgen de Guadalupe. Algunos grafitis (que en la colonia abundan) expresaban temáticas religiosas: la última cena, Cristo crucificado, vírgenes, etcétera. Un hecho relevante fue que durante todo el recorrido no hubo miembros de La Luz del Mundo deambulando por las calles, algo muy común en esta zona (las mujeres integrantes de La Luz del Mundo se identifican visualmente por usar falda larga hasta los tobillos, cabello largo recogido hacia atrás, sin maquillaje y sin accesorios).

A lo largo de su ruta, la procesión hizo tres altos en altares dispuestos con flores y una pequeña imagen de Cristo. En cada alto, la joven que portaba la Biblia hacía una breve lectura de la misma. Se usó un altavoz para que la lectura fuera escuchada por la mayoría de los integrantes de la procesión y espectadores. El recorrido se realizó por calles colindantes con El Bethel, en las inmediaciones de la colonia Villas de Guadalupe (y parte de la colonia Heliodoro Hernández, colindante tanto con El Bethel como con Villas de Guadalupe). Después de casi 45 minutos de procesión, se llegó nuevamente al punto de partida, es decir, frente al templo. Quienes llevaban en andas 
a la Virgen ingresaron al templo, mientras el grueso de las personas que marchaban en procesión deshizo la fila y se esparció: unos se dirigían hacia sus casas y sus figuras se iban perdiendo entre las calles; otros se quedaban por breve tiempo a comprar algún alimento en puestos instalados frente al templo. Poco a poco se fueron yendo, sólo permanecieron un rato más las vendedoras de los puestos, que se apresuraban a guardar sus implementos de vendimia para emprender el retiro.

Las procesiones son rituales que narran una perspectiva específica de la sociedad. Son metalenguajes sobre la sociedad (Grimes, 1985). Desde el enfoque del antropólogo Víctor Turner sobre el proceso ritual (1987), la Marcha del Silencio inscribe relaciones dentro de un proceso trifásico continuo y lineal; dentro de este proceso la procesión en su conjunto, como colectivo andante, corresponde al estado intermedio, de transición, llamado "liminal".

Quienes participan en la marcha se desprenden tanto de la vida cotidiana de la colonia como de su vida diaria personal para convertirse en pasajeros dentro de un territorio intersticial-liminal. Posteriormente, al término de la marcha, vuelven a incorporarse tanto a la cotidianidad de la colonia como a sus propias rutinas. La marcha comunica y expresa algo sobre esa cotidianidad. Sin embargo, no queremos emprender un análisis sobre la communitas, momento subjetivo y emotivo propio de los estados liminales en donde se regenera o se consolida la estructura. Más bien queremos proponer que entre el estado liminal y la zona fronteriza, tal y como aquí se entiende esta última, hay una identificación y analogía; es decir, los acontecimientos, procesos y relaciones operados por los sujetos durante los procesos rituales configuran intersticios simbólicos que denotan aspectos de la sociedad y de su estructura social.

En su estudio sobre los carnavales, las procesiones y desfiles cívicos en Brasil, Roberto Da Matta (2002) identifica respectivamente a cada uno de estos rituales con la inversión, la neutralización y el reforzamiento de la estructura social jerárquica. En el carnaval se invierten los papeles (el pobre es rico, el hombre es mujer, etcétera); en los desfiles se refuerza la estructura al enfatizar el predominio de la autoridad, particularmente la vinculada al poder del Estado (y los militares); y en las procesiones se neutraliza lo anterior, pues son rituales que "por el hecho de juntar en un mismo momento al pueblo y las autoridades, los santos y los pecadores, los hombres sanos y 
los enfermos actualizan en su discurso una neutralización sistemática de posiciones, grupos y categorías sociales, ejerciendo una especie de Pax Catholica" (Da Matta, 2002:81).

Llama la atención el aspecto heterogéneo de las procesiones al vincular elementos tanto de reforzamiento como de inversión, pues indica la convergencia y el cruce de elementos descentrados de núcleos de sentido diversos. Esto es, las procesiones hacen posible la conexión con la inversión porque en general las fiestas religiosas locales -aquellas que celebran a santos, santas y vírgenes-, aunque sean ceremonias con alto grado de devoción solemne, finalizan con una fiesta. En el caso de esta Marcha del Silencio, al invertir, reforzar o neutralizar relaciones, los sujetos generan o reproducen cultura y por ende construyen fronteras simbólicas. Además, esto es así porque la cotidianidad a la cual está referida la marcha es parte de una realidad mayor. En primera instancia, forma parte de un contexto inmediato religioso -la colonia-, pero a la vez, también es parte de un contexto más amplio: el campo religioso. En esta orientación, la procesión se inscribe dentro de la perspectiva católica y, por su condición de ritual, se posiciona en la zona límite del campo al entrar en interacción con otros límites, otras fronteras religiosas dentro de la colonia. Para quien participa y para quien no, comunica una adhesión a -o separación de- la perspectiva católica. En ese sentido, la procesión es más que un ritual que neutraliza las relaciones sociales y la estructura jerárquica (Da Matta, 2002) porque ocurre en un contexto local de diversidad religiosa, de tal forma que nos habla de un discurso de sentido intrínseco al catolicismo, pero externo y contrario a otras religiones. Así, la Marcha del Silencio propicia una zona fronteriza en donde converge lo diverso, contradictorio y conflictivo de una estructura social jerárquica (la de la sociedad en su conjunto) y a la vez la estructura de un campo religioso en transformación hacia la diversidad, pero también en clave de estructura jerarquizada.

El desplazamiento de la procesión sobre una ruta preestablecida -que sólo adquiere significado en el momento en que los "marchistas" la transitan- va delimitando el espacio físico, lo va seccionando y, con ello, lo va figurando simbólicamente; va bordeando, es decir, va haciendo y remarcando tanto los límites y el centro (la comunidad católica) del que depende como los límites de otros centros (aquellas comunidades que pertenecen a religiosidades no católicas como La Luz del Mundo). 
En estas líneas fronterizas se entreteje un espacio en el que convergen los contactos entre sujetos religiosamente heterogéneos que canalizan contradicciones y conflictos.

La zona de contacto es emergente y, por lo mismo, cabe lo posible y lo que está por darse. Rosaldo (1999) y Bhabha (2003) ven en estos intersticios la emergencia de figuraciones culturales inéditas que replantean las ideas sobre la cultura homogénea, compartida y esencializada. La procesión como flujo, como símbolo itinerante, desestabiliza la coherencia de la cultura encerrada en el territorio físico discreto y se dirige hacia los límites (físicos y simbólicos). Desde una perspectiva física y geográfica, la marcha circunda los límites de la colonia El Bethel y al interior de Villas de Guadalupe remarca los límites frente a aquellas comunidades ajenas a la procesión. Sin embargo, el desplazamiento cultural que representa la procesión ocasiona que lo fijo (las calles, los grafitis), incluyendo la ausencia de personas no católicas, cobre una condición de frontera. Así, al paso de la procesión, que va remarcando límites, se va configurando un entramado intersticial donde se hacen notar los contactos que desvelan la hegemonía, las contradicciones y la multiculturalidad religiosa.

La procesión ocurre en un campo religioso que, si bien es dominado por la Iglesia católica, en contextos específicos como el señalado, de multirreligiosidad, configura espacios fronterizos que dan cuenta de procesos descentrados y, a la vez, describen nuevas formas (fronterizas) mediante las cuales se reconfigura lo religioso.

\section{Desfile del 20 de noviembre en El Bethel}

Ahora nos referiremos a otro evento cuyo carácter es de índole aparentemente secular, pero que entraña profundos sentimientos cívicos patrios, a manera de lo que Bellah (2007) denomina religión civil. El desfile es organizado por docentes de la escuela secundaria pública situada en la colonia El Bethel y en él participan todas las escuelas públicas de la colonia, esto es: preescolar, primaria y secundaria.

Como se sabe, la escuela pública es el conducto a través del cual el Estado mexicano inculca a las nuevas generaciones un sistema de pensamiento, valores y acción que, en el caso de nuestro país, es -o debe ser- laico. Entre los muchos y variados valores que pretende transmitir destacan aquellos 
de profundo sentimiento nacionalista (Latapí, 2001). Generalmente, esta inculcación se realiza a través de un conjunto de rituales cívicos, como la conmemoración del 20 de noviembre, día de la Revolución mexicana. Cabe recordar que El Bethel es una colonia cuya población es mayoritariamente adherente a La Luz del Mundo, y que además, esta Iglesia mantiene una hegemonía territorial a escala local; en consecuencia, todas las instituciones, incluyendo las gubernamentales, están permeadas por los influjos religiosos (sistema de creencias y prácticas) de dicha Iglesia. La escuela, aunque representa un poder sólido y supuestamente omnipresente en todo el territorio nacional -es decir, representa la presencia local del poder del Estado-, también es penetrada, como veremos a continuación, por la hegemonía que ejerce La Luz del Mundo en la colonia.

El desfile de la Revolución Mexicana (y en general otros desfiles, como el del día de la Independencia de México o el de la primavera, por ejemplo) es una manera en que la escuela se involucra con la colonia o "comunidad", como es habitual que los docentes se refieran al entorno en donde se emplaza el centro escolar en el que laboran.

El desfile tiene una primera intención estipulada en el marco jurídico regulador de la educación pública, en donde se indica la necesidad y pertinencia de que las escuelas se vinculen con su entorno social. ${ }^{2}$ Esto es, una disposición jurídica que promueve la participación de la "comunidad" en los quehaceres de la escuela y el involucramiento de la escuela con la comunidad. Sin embargo, hay que agregar otra intención: la formación de ciudadanos con fuertes vínculos emocionales con la nación, es decir, la construcción de un sentimiento nacionalista y patriótico en los estudiantes.

El desfile tiene su itinerario sobre las calles principales de las colonias El Bethel, Villas de Guadalupe y, en menor medida, Heliodoro Hernández, de manera que es visto por la mayoría de los habitantes del área. En este sentido, es un recorrido estratégico que tiene como fin ser visto y comunicar mensajes cívicos nacionalistas entre los espectadores mediante diversos símbolos arrancados de diferentes sistemas -el civil, el cívico y el religiosoy trasplantados al desfile, en el cual, por tratarse de una actividad escolar,

2 Véase la Ley General de Educación Pública, en especial el apartado denominado "Participación Social". 
predominan los símbolos cívicos laicos. No obstante, como se verá en breve, este predominio no excluye la influencia de la esfera religiosa.

En el desfile participan tres tipos de grupos claramente identificados: $a$ ) grupos escolares de preescolar, primaria y secundaria; $b$ ) grupos religiosos, en este caso representados por una Brigada de Rescate de La Luz del Mundo denominada "Escuderos de Cristo"; y c) grupos civiles o que representan al gobierno local: un grupo de policías del Ayuntamiento que coordinó la vialidad y seguridad y un grupo de primeros auxilios de la Cruz Verde, además de los miembros del Comité de Vecinos (todos miembros de La Luz del Mundo) que prestaron apoyo logístico y el equipo de sonido a los maestros para narrar el desfile.

Los desfiles, dice Grimes (1985), son procesiones secularizadas que

Tienen por fin la mera diversión o la exhibición de sentimientos patrióticos y del poderío militar. Pero el patriotismo puede ser tan absoluto en su exigencia como la religión. Las actividades cívicas y civiles simbolizadas en los desfiles pueden otorgar fuertes sanciones al cumplimiento de valores sociales. A este respecto son tan comprometedores y por tanto tan sagrados como los valores religiosos (Grimes, 1985:60).

El desfile, en general, ocurrió de la siguiente manera: en las calles más céntricas de la colonia El Bethel (llamadas Betania y Betlem) se aglutinaron desde las ocho de la mañana los alumnos y los maestros que desfilarían, además de las mamás de los estudiantes. Más tarde, ya casi a las nueve de la mañana, sobre la banqueta, algunas mujeres -que por su vestimenta se distinguían como adherentes de La Luz del Mundo- instalaron sillas desplegables para presenciar cómodamente el paso de los "contingentes" desfilando.

El desfile irrumpe en la movilidad cotidiana de los habitantes de la colonia. El día del desfile se interrumpió por más de media hora el tráfico vehicular en la calle principal por donde transitan las rutas de camiones de transporte de pasajeros y autos particulares. En estas calles se congregaban alumnos vestidos de revolucionarios; alumnas de secundaria, las bastoneras, con faldas cortas y blusas de tela roja brillante y botas negras; alumnos luciendo camisetas del equipo de fútbol de la secundaria; alumnas de primaria y preescolar con trajes folclóricos representativos de las diferentes regiones del país. El grupo de rescate de La Luz del Mundo, con diez o doce 
integrantes (entre ellos dos mujeres), sobresalía de todos los demás por su vestimenta militar. El estruendo de la Banda de Guerra que ensayaba daba al nutrido conglomerado un halo marcial e intensificaba la expectación del inminente inicio. Maestras y maestros se desplazaban y daban indicaciones para que los grupos se formaran en cierto orden planeado con anterioridad. En la oficina del Comité de Vecinos (que se ubica en un edificio propiedad de La Luz del Mundo) se instaló un equipo de sonido; desde ahí, dos maestros y una maestra daban indicaciones por micrófono para que cada grupo tomara su lugar.

Casi en punto de las nueve de la mañana, los grupos de alumnos y sus respectivos maestros formados en línea iniciaron el desfile. Al frente se desplazaba lentamente una patrulla con la torreta de luces encendida para garantizar la fluidez del desfile. Le seguían los "contingentes" escolares y por último el grupo de rescate de La Luz del Mundo. Al paso por las oficinas del Comité de Vecinos, donde se instalaron los amplificadores, la maestra y los dos maestros narraron el desfile por micrófono. La narración fue importante en términos de comunicar valores cívicos y dar un apoyo cognitivo a los sentimientos nacionalistas expresados en la simbólica del desfile. Los narradores ofrecieron una interpretación de la Revolución mexicana mediante la descripción del vestuario de los alumnos que desfilaban o de las rutinas acrobáticas que iban ejecutando. Simultáneamente, insistían en reconocer el esfuerzo -"el entusiasmo"- de los participantes -de los chiquitines- en el desfile, por lo cual solicitaban "un fuerte aplauso" de la concurrencia.

El desfile en sí mismo representa valores como nacionalismo y patriotismo mediante un conjunto de símbolos que unen e integran una diversidad de significados para los diferentes grupos participantes. Tanto los grupos civiles, religiosos y cívicos como los habitantes (católicos y de La Luz del Mundo) que presenciaron el desfile significan, a partir de su propia visión, la conmemoración de la Revolución mexicana.

Para el grupo religioso de La Luz del Mundo, cumplir con preceptos cívicos es cumplir con la ética religiosa: "buenos cristianos, buenos ciudadanos", pues suelen combinar ambas dimensiones simbólicas sin ninguna contradicción o conflicto. Para los grupos escolares (principalmente docentes y directivos) conscientes de su entorno religioso, es una manera de mostrar a la "comunidad" su presencia y comunicar valores cívicos. Para diversos 
grupos, católicos y de La Luz del Mundo, lo cívico-nacionalista y patriótico, como un proceso simbólico integrador, alcanza su propósito.

El vínculo entre lo religioso y lo cívico (secular) no implica una articulación de las instituciones escolares y religiosas durante el desfile, sino una integración de símbolos (Grimes, 1985). Las instituciones mantienen su centro autonómico, no así los símbolos. El nacionalismo laico se integra al nacionalismo religioso de los "Escuderos de Cristo". En este sentido, el desfile refracta la interacción entre los símbolos religiosos, en especial los de La Luz del Mundo, y los cívicos de los grupos escolares. La vestimenta de los "Escuderos de Cristo", expresión explícita de los símbolos religiosos, se articula a los significados patrióticos y nacionalistas del vestuario de algunos grupos escolares alusivo a lo mexicano (como el charro) y al hecho mismo de la revolución (como las soldaderas). Ambas expresiones configuran un sistema andante de significados que, aunque momentáneo, es eficaz en comunicar e inculcar en los participantes y espectadores profundos sentimientos nacionalistas y religiosos.

La narración de los maestros refuerza la inculcación del sentimiento nacionalista a todos los participantes del desfile. Por ejemplo, la maestra encargada de narrar el desfile pronunciaba entusiasmada: "Demos un fuerte aplauso a estas pequeñitas y pequeñitos [...] haciendo sus peripecias vestidas hermosamente de rancheras, démosles un fuerte aplauso. ¡Aplauso fuerte para ellas! [... $]_{i}$ Y ese entusiasmo que están demostrando esas pequeñitas! [...] ¡Esas famosas revolucionarias que participaron en nuestra gran revolución! ¡Venga de ahí un fuerte aplauso!”. Pero también, en otro momento de la narración, agregó: "[...] al grupo de rescatistas de esta comunidad de Cristo, un aplauso fuerte para ellos $[\ldots]$ ¡Un aplauso fuerte para ellos, que se oiga, que se oiga!”.

La narración del desfile se fusionó con la narrativa andante de quienes se desplazaban. Ésta, caracterizada por el movimiento, el efecto visual y sonoro (música regional y moderna, los tambores y trompetas de la Banda de Guerra, gritos festivos y en general el sonido del desplazamiento) se complementó con las explicaciones y el discurso oral emotivo de los narradores. Es claro que el desfile está configurado a partir de un sistema de símbolos cívicos que procuran exaltar sentimientos patrióticos de unidad dentro de una narrativa histórica nacional. El desfile comunica la historia, pero la actualiza no sólo para los participantes, en su mayoría agentes escolares, sino para el 
público espectador en general, integrado casi en su totalidad por católicos y miembros de La Luz del Mundo.

Al ser ritualizada en el desfile, la Revolución mexicana -uno de los mitos mexicanos según Florescano (2004) - alcanza una eficacia simbólica más allá de los agentes escolares inmersos en las delimitaciones de la institución educativa. La idea de nación, de identidad nacional, de cultura nacional compartida e inculcada a través de la escuela pública, configura una frontera simbólica identificada con la nación, con un territorio. Sin embargo, la frontera no está predeterminada de forma unívoca y homogénea; como se vio, puede incorporar elementos que contradicen la idea de nación y Estado laico. La presencia de los "Escuderos de Cristo" en el desfile cuestiona los límites de nación homogénea, pero al mismo tiempo refuncionaliza la idea de una nación, una comunidad heterogénea que comparte elementos y sentimientos.

El desfile como espacio intersticial (es también un ritual de pasaje) fronterizo pone de relieve el cruce de límites diversos; ahí se congregan límites fronterizos diferenciados que comparten una historia y, a la vez, se revelan formas que de alguna manera van minando, disolviendo o fragmentando la misma idea de nación.

El desfile de la Revolución mexicana refuerza simultáneamente dos estructuras jerárquicas dominantes: la del Estado mexicano y la de la Iglesia, pero en este caso no la católica, sino la de La Luz del Mundo. Lo primero, el reforzamiento del Estado, se expresa mediante símbolos cívicos patrióticos de envergadura nacional. Lo segundo cobra expresión a través de la puesta en escena de una simbólica religiosa no católica, y con ello hace patente, por un lado, la conformación de un Estado-nación integrado multirreligiosamente, y por otro, la fisura del Estado laico que no separa lo religioso de la vida pública.

De tal suerte, el desfile combina lo barrial multicultural con una cultura nacional y nacionalista homogénea, y a la vez refuerza dos estructuras (el Estado y la Iglesia) políticamente contradictorias.

\section{Breve análisis y conclusiones}

La frontera remite al encuentro de límites, es decir, a contactos entre elementos y procesos heterogéneos. Es, entonces, en donde se definen y a la 
vez se redefinen, según hemos anotado, elementos y procesos laicos y religiosos. La procesión en la colonia Villas de Guadalupe y el desfile en la colonia El Bethel ejemplifican la configuración, debido a la convergencia de lo religiosamente heterogéneo, de zonas fronterizas. Sin embargo, la frontera no está pre-construida, su configuración obedece a actos de recreación mediante los cuales se actualiza y se inventa cotidianamente, cada vez que los sujetos interactúan. Son límites que adquieren una condición de frontera en virtud de la interacción y prácticas entre sujetos que pertenecen a núcleos religiosos diversos. En este sentido, la frontera es contingente y emergente, y particularmente es "porosa" (Grimson, 2003) en la medida en que permite influjos interconectados en los límites.

En la sociedad contemporánea, Grimson expresa la problematización de frontera de la siguiente manera:

Las fronteras pueden desplazarse, desdibujarse, trazarse nuevamente, pero no pueden desaparecer: son constitutivas de toda vida social. Un proyecto de abolición de todas las fronteras estaría necesariamente destinado a fracasar, ya que no puede vivirse fuera del espacio y sin categorías de clasificación. Más bien, por un lado, el debate es dónde colocar fronteras, y por otro, cuándo pretender cruzarlas, debilitarlas, asumirlas reflexivamente o reforzarlas. Difícilmente convenga adjuntarle un sentido unívoco a 'frontera' y adoptar una actitud homogénea hacia las diversas fronteras con las que vivimos (Grimson, 2003:22).

La frontera es entonces un proceso en el que emergen sentidos multivalentes (como la idea de interfaz manejada por Long [2007]). Es una topología situada en los intersticios e intersecciones sociales, los cuales generan una lógica práctica específica, alejada de los procesos centrados. La presencia de grupos religiosos minoritarios dentro de cada colonia señala que también estos grupos deben estar construyendo sus límites para diferenciarse, lo cual indica la necesidad de seguir indagando cómo se llevan a cabo estos procesos, cómo ciertos grupos religiosos son cada vez más visibles en la esfera pública local. Esta visibilidad, como se vio, es relativa pues depende de cómo se ejerce el poder localmente.

El poder es fundamental para construir fronteras, y en un contexto como el anotado, las zonas fronterizas se construyen a través de prácticas 
que, aunque descentradas, obedecen a lineamientos integrados a relaciones asimétricas de dominación.

Entonces, volviendo a las preguntas iniciales de esta investigación, la construcción de zonas fronterizas religiosas, en una sociedad cada vez más multicultural como la mexicana, expresa procesos conflictivos y de exclusión, aunque también de oposición a lo hegemónico. La lógica de la cultura es cristalizar un núcleo que define e identifica a quienes la comparten; lo que ocurre en las zonas fronterizas religiosas -como los procesos rituales anotados- indica no sólo la persistencia y quizás el reforzamiento de dicho núcleo, sino particularmente las modificaciones y desplazamientos de los contenidos simbólicos centrados, los cuales se vuelven periféricos y se desplazan hacia los límites. De esta forma, la cultura no puede entenderse como un sistema de símbolos permanentes, cristalizados e inamovibles; desde la perspectiva de la frontera simbólica, la cultura se percibe en movimiento, en construcción; esto es, está inserta en un contexto social históricamente estructurado.

En la sociedad contemporánea, las zonas fronterizas marcan una disyuntiva: ser los intersticios en los cuales se manifiesta el multiculturalismo estructurado por el poder, la verticalidad, las contradicciones y exclusión social; o ser un espacio intercultural dirigido hacia nuevos reacomodamientos más horizontales y de mayor participación.

En otros términos, y retomando lo que ocurre en el campo religioso, la disyuntiva está en la conformación de sociedades religiosas que buscan cristalizar (esencializar) y socializar (o imponer) su ethos religioso remarcando sus núcleos comunitarios, o sociedades religiosas interesadas en una nueva forma de relacionarse con lo trascendente y con la sociedad, permitiendo explícita o implícitamente el cruce de sus límites. Todo esto nos habla de las transformaciones de la sociedad moderna en general y del campo religioso en particular.

Cabe decir brevemente, de acuerdo con los casos presentados, que si la relación entre sociedad y religión en México se caracteriza por aspectos de condición de frontera, es posible que de manera inconsciente (o no tanto) las formas religiosas (y no sólo la católica) intenten organizar la vida en todos los aspectos, incluyendo el político.

El desfile y la procesión en las calles de las colonias mencionadas son rituales en los que se expresa la sociedad. Nos comunican de forma diversa aspectos de una misma realidad tanto local como nacional. Esto significa 
que la realidad religiosa y secular concreta es múltiple y diversa en su constitución. Pero, además, significa que esa realidad constituida por lo religiosamente diverso se expresa de forma fronteriza.

En la sociedad actual, si bien los rituales expresan una realidad social jerárquica, tal jerarquización se empieza a constituir de forma distinta. Lo comunitario y bien delimitado tiende hacia los límites y es en estas zonas fronterizas que la jerarquía se activa en virtud de procesos simbólicos articuladores de lo divergente que parecieran flexibilizar las relaciones jerárquicas y hegemónicas. De esta manera, las zonas fronterizas simulan (además de reforzar, neutralizar o invertir) una estructura social altamente jerárquica (y desigual). Pero también debemos ver en las zonas fronterizas lo que Da Matta advierte acerca de los rituales:

De modo que en el ritual, y sobre todo en el ritual colectivo, es donde la sociedad puede tener (y en efecto tiene) una visión alternativa de sí misma. Pues es ahí donde sale de sí misma y llega a un terreno ambiguo en el cual no está como es normalmente ni como podría ser, ya que, por definición, el ceremonial es un estado pasajero. Pero quizá tal estado pueda permanecer (Da Matta, 2002:51).

En las zonas fronterizas ya no ocurre lo irrelevante e insignificante, sino lo socialmente relevante y central. Permite pensar de forma compleja los procesos sociales, las relaciones y las interacciones entre sujetos. Desde esta perspectiva fronteriza, la cultura ya no es una forma fija o estática ni coherente, sino un entramado simbólico operado por los sujetos bajo criterios estratégicos y tácticos. Corresponde a los agentes operarla reflexivamente dentro de contextos históricamente construidos. La cultura alude a procesos desestabilizadores, contradictorios, hegemónicos y conflictivos (quizá más propios de la existencia humana), pero también es una manera de ir entretejiendo alternativas sociales a tales procesos. Lo mismo vale para el campo religioso: prácticas simbólicas históricamente construidas y estructuralmente situadas en donde las personas interactúan en condiciones de frontera.

\section{Bibliografía}

Barth, Frederick (1979), "Introducción", Los grupos étnicos y sus fronteras. La organización social de las diferencias sociales, México, Fondo de Cultura Económica. 
Bellah, Robert N. (2007), "Religión civil en América", en Josetxo Beriain y Maya Aguiluz (eds.), Las contradicciones culturales de la modernidad, España, Anthropos.

Bhabha, Homi K. (2003), El lugar de la cultura, Argentina, Manantial.

Martín Barbero, Jesús (2005), "Identidad y diversidad en la era de la globalización”, en Bárbara Negrón (ed.), Diversidad cultural. El valor de la diferencia, Chile, Lom, Consejo Nacional de la Cultura y las Artes, pp. 29-43.

Cohen, A.P. (1995), The Symbolic Construction of Community, Londres y Nueva York, Routledge.

Da Matta, Roberto (2002), Carnavales, malandros y héroes. Hacia una sociología del dilema brasileño, México, Fondo de Cultura Económica.

De la Torre Castellanos, Renée (1995), "Guadalajara: la perla de La luz del Mundo", en Renglones, núm. 30, México, ITEso.

Florescano, Enrique (2004), La bandera mexicana. Breve historia de su formación y simbolismo, México, Fondo de Cultura Económica.

Geertz, Clifford (1990), La interpretación de las culturas, España, Gedisa.

Giménez, Gilberto (1999), “Territorio, cultura e identidades. La región socio-cultural”, en Estudios sobre las culturas contemporáneas, época II, vol. V, núm. 9, Universidad de Colima, Colima.

Grimes, Ronald L. (1985), Símbolo y conquista. Rituales y teatro en Santa Fe, Nuevo México, México, Fondo de Cultura Económica.

Grimson, Alejandro (2003), "Introducción”, en S. Michaelsen y E. Jonson (comps.), Teoría de la Frontera. Los límites de la política cultural, España, Gedisa.

Latapí Sarre, Pablo (2001), La moral regresa a la escuela. Una reflexión sobre la ética laica en la educación mexicana, México, Universidad Nacional Autónoma de MéxicoCentro de Estudios Sobre la Universidad.

Pratt, Louise Mary (1996), "Apocalipsis en los Andes: zonas de contacto y lucha por el poder interpretativo", conferencia pronunciada en el Banco Interamericano de Desarrollo en Washington, D. C, el 29 de marzo de 1996, en el marco del Programa de Conferencias del Centro Cultural del BID, Centro Cultural del BID, marzo de 1996, núm. 15.

Rosaldo, Renato (1999), Cultura y verdad. Nueva propuesta de análisis social, México, CNCA, Grijalbo.

Solís Domínguez, Daniel (2010), "Religión y construcción simbólica de territorios identitarios urbanos en la ciudad de Guadalajara: El Bethel y Santa Cecilia", en Revista Cuicuilco, Nueva Época, ENAH, núm. 49, julio-diciembre, pp. 62-88.

Tylor, Edward B (1992), "Cultura primitiva”, en P. Bohnnan y M. Glazer, Antropología. Lecturas, España, Mc Graw Hill.

Artículo recibido el 11 de agosto de 2011 Artículo aprobado el 30 de enero de 2011 